\title{
Oscillations and residual displacements of buildings of varying heights and widths, constructed on elastic-plastic base
}

\author{
Zaven Ter-Martirosyan ${ }^{1}$, Evgeniy Sobolev ${ }^{1, *}$, Armen Ter-Martirosyan ${ }^{1}$ and Aleksandra \\ Bestuzheva $^{1}$ \\ ${ }^{1}$ Moscow State University of Civil Engineering, 129337, Moscow, 26 Yaroslavskoe Shosse, Russia
}

\begin{abstract}
Modern regulations in the field of design and construction of buildings in seismically dangerous areas provide for stability calculation of bases, foundations and underground structures, i.e. calculations for the first group of limited states. At the same time, calculations for the second group of limited states, like deformations (yields, relative difference in yields), as a rule, are not fulfilled. This state of affairs is due to insufficient knowledge of the issues of appearance and development of additional stress and strain in ground arrays during seismic influences, that ultimately leads to residual yields and rolls of foundations of industrial and civil buildings. Essentially, residual displacements depend on the type and intensity of dynamic effects, as well as on the model foundation soils. At the same time, the most important factor is the compulsory registration of collaboration between the subgrade and the structure. Therefore, quantification of additional residual displacements of foundations of industrial buildings and structures under dynamic loads, is an actual problem of the modern earthquake-resistant construction.
\end{abstract}

\section{Introduction}

The strength and stability of buildings and constructions under static and seismic actions is determined by the nature of the system interaction "foundation - structure". Formulation of the problem is to analyze, under different seismic actions, the forms of vibrations of buildings and structures of different width and height on the two-layer base. At the same time, significant attention is paid to the assessment of movements of residual mass of soil, containing underground part of the structure.

The most significant factor in determining the seismic resistance of a structure is the intensity of seismic effects in the area of its construction. Another major factor is the ratio of primary natural vibration frequencies of "base - construction" system and the seismic effect. In case of coincidence of these frequencies, the resonance phenomenon can lead to loss of stability of structures, even at low intensity of the seismic action [1].

* Corresponding author: e.s.sobolev@mail.ru 


\section{Method}

For analysis of the Stress-Strain State (SSS) of soil mass enclosing the underground part of the building, as well as in order to assess the impact of various factors on the value of the residual deformation of the compressible base, in the Software Package (SP) PLAXIS 2D 2016 a mathematical modeling was performed for the systems consisting of: structures with different geometrical dimensions (width and number of floors), compressed two-layered soil foundation, based on different models (model Mohr-Coulomb and model "hardening soil model with small-strain stiffness").

Quantitative prediction of stress-strain state in heterogeneous base grounds (in the present study defined as a two-layer base) structures under static and seismic action is necessary to ensure the normal conditions of facilities exploitation $[2,3]$.

In order to do this, one must take into account seismicity of the construction site accommodation area on the basis of engineering-geological conditions as well as physical and mechanical properties of the foundation soil. In this study, seismic effects are defined in accordance with accelerograms recommended by the MGSN (Moscow City Construction Regulations) 4.19-05 Multifunctional High-Rise Buildings and Complexes (Figure 1).

At the same time, in dynamic calculation module the SP PLAXIS 2D 2016 allows to directly provide for the specified accelerogram and to use it in calculation of SSS of subgrade under seismic impacts.

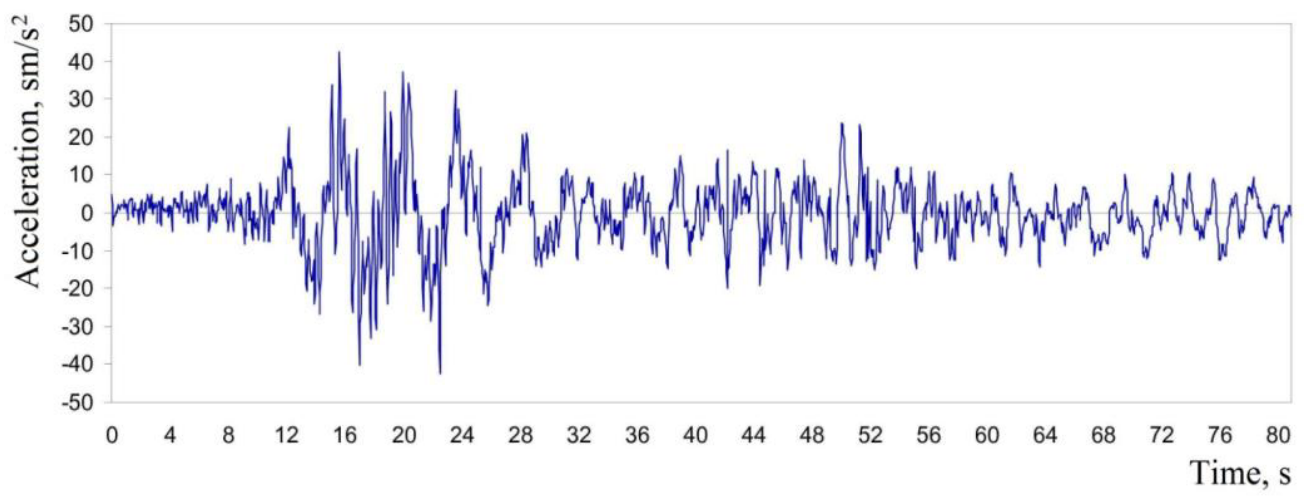

Fig. 1. Earthquake analogue accelerogram, used in FEM (Finite Element Method) calculations (in accordance with MGSN 4.19-05 Multifunctional High-Rise Buildings and Complexes).

In this paper, a two-layer base is analyzed. The top layer with thickness of $15 \mathrm{~m}$ is represented by silty-clay soil. The bottom layer consists of sandy soil with thickness of 25 $\mathrm{m}$. The foundation soil properties are presented in Table 1 .

The first model used in mathematical modeling is the model of Mohr-Coulomb. It represents a model of the "first level", which includes only a real number of features of the soil behavior. Despite the fact that increase in stiffness can be considered with depth, the Mohr-Coulomb model does not account for dependence of hardness neither on stress nor on the stress trajectory, and also on the deformation anisotropy. The state of stress at break can be described by the Mohr-Coulomb criterion, with effective strength parameters $\varphi^{\prime}$ (internal friction angle) and $\mathrm{c}^{\prime}$ (specific cohesion) $[4,5]$.

The second model used in mathematical modeling - the soil model "hardening soil model with small-strain stiffness" (HSSMALL), while taking into account the soil stiffness at small strains, is based on a fairly well-known elastic-plastic model of hardening soil (hardening soil model) and uses almost the same set of parameters. In fact, description of changes in rigidity due to magnitude of deformation requires only two additional parameters: initial shear modulus and shear modulus of the ultra-low deformations of $\mathrm{G}_{0}$; 
shear strain rate $\gamma_{0,7}$, wherein secant shear modulus $G_{s}$ decreases to about $70 \%$ of the magnitude of $\mathrm{G}_{0}$.

Table 1. Physical and mechanical properties of soils.

\begin{tabular}{|c|c|c|c|c|}
\hline Parameter & Name & $\begin{array}{l}\text { Upper clayey } \\
\text { layer }\end{array}$ & $\begin{array}{l}\text { Lower sandy } \\
\text { layer }\end{array}$ & Unit \\
\hline \multicolumn{5}{|l|}{ General } \\
\hline Material model & Model & HS small & HS small & - \\
\hline Type of material behaviour & Type & Drained & Drained & - \\
\hline $\begin{array}{l}\text { Soil unit weight above phreatic } \\
\text { level }\end{array}$ & $\gamma_{\text {unsat }}$ & 16 & 20 & $\mathrm{kN} / \mathrm{m}^{3}$ \\
\hline $\begin{array}{l}\text { Soil unit weight above phreatic } \\
\text { level }\end{array}$ & $\gamma_{\text {sat }}$ & 20 & 20 & $\mathrm{kN} / \mathrm{m}^{3}$ \\
\hline \multicolumn{5}{|l|}{ Parameters } \\
\hline $\begin{array}{l}\text { Secant stiffness in standard } \\
\text { drained triaxial test }\end{array}$ & $E_{50}^{\text {ref }}$ & $2.0 \cdot 10^{4}$ & $3.0 \cdot 10^{4}$ & $\mathrm{kN} / \mathrm{m}^{2}$ \\
\hline $\begin{array}{l}\text { Tangent stiffness for primary } \\
\text { oedometer loading }\end{array}$ & $E_{\text {oed }}^{\text {ref }}$ & $2.561 \cdot 10^{4}$ & $3.601 \cdot 10^{4}$ & $\mathrm{kN} / \mathrm{m}^{2}$ \\
\hline Unloading / reloading stiffness & $E_{u r}^{r e f}$ & $9.484 \cdot 10^{4}$ & $1.108 \cdot 10^{5}$ & $\mathrm{kN} / \mathrm{m}^{2}$ \\
\hline $\begin{array}{l}\text { Power for stress-level dependency } \\
\text { of stiffness }\end{array}$ & $m$ & 0.5 & 0.5 & - \\
\hline Cohesion & $c_{\text {ref }}^{\prime}$ & 10 & 5 & $\mathrm{kN} / \mathrm{m}^{2}$ \\
\hline Friction angle & $\varphi^{\prime}$ & 18 & 28 & $\circ$ \\
\hline Dilatancy angle & $\psi$ & 0 & 0 & $\circ$ \\
\hline $\begin{array}{l}\text { Shear strain at which } G_{s}= \\
0.722 G_{0}\end{array}$ & $\gamma_{0.7}$ & $1.2 \cdot 10^{-4}$ & $1.5 \cdot 10^{-4}$ & - \\
\hline $\begin{array}{l}\text { Shear modulus at very small } \\
\text { strains }\end{array}$ & $G_{0}^{\text {ref }}$ & $2.7 \cdot 10^{5}$ & $1.0 \cdot 10^{5}$ & $\mathrm{kN} / \mathrm{m}^{2}$ \\
\hline Poisson's ratio & $\nu_{u r}^{\prime}$ & 0.2 & 0.2 & - \\
\hline
\end{tabular}

Differences between static and dynamic stiffness of soil, explained by the nature of stressing (e.g., by inertial forces and by strain rate effect), rather than by magnitude of the applied strain, which in dynamic conditions is usually not so large. Since inertia forces and rate of deformation have very little effect on the initial stiffness of soil, the terms "dynamic stiffness" and "stiffness at small strains" may actually be considered as synonyms.

The SSS of an interacting with structures two-layer base is significantly affected by the rigidity of construction, by the upper and lower base layers and their relationship, as well as by the elastic-plastic properties of soils.

SSS calculations completed for double-layer base interacting with buildings of different heights and widths have shown that registration of elastic-plastic properties of soil under static and seismic effects leads to additional residual stresses and displacements. However, frequency of normal vibrations of buildings is significantly different, while depending on the geometrical dimensions of the building $[6,7]$.

With increase in the number of stores of buildings, the effect of seismic loading on SSS of soil base, enclosing the underground part of the building, is growing significantly. In the contact zone "foundation - base" emerges an additional stress and strain, which leads to additional residual stress and displacement, as well as to formation of local zones of limited state of soil elastic equilibrium. 

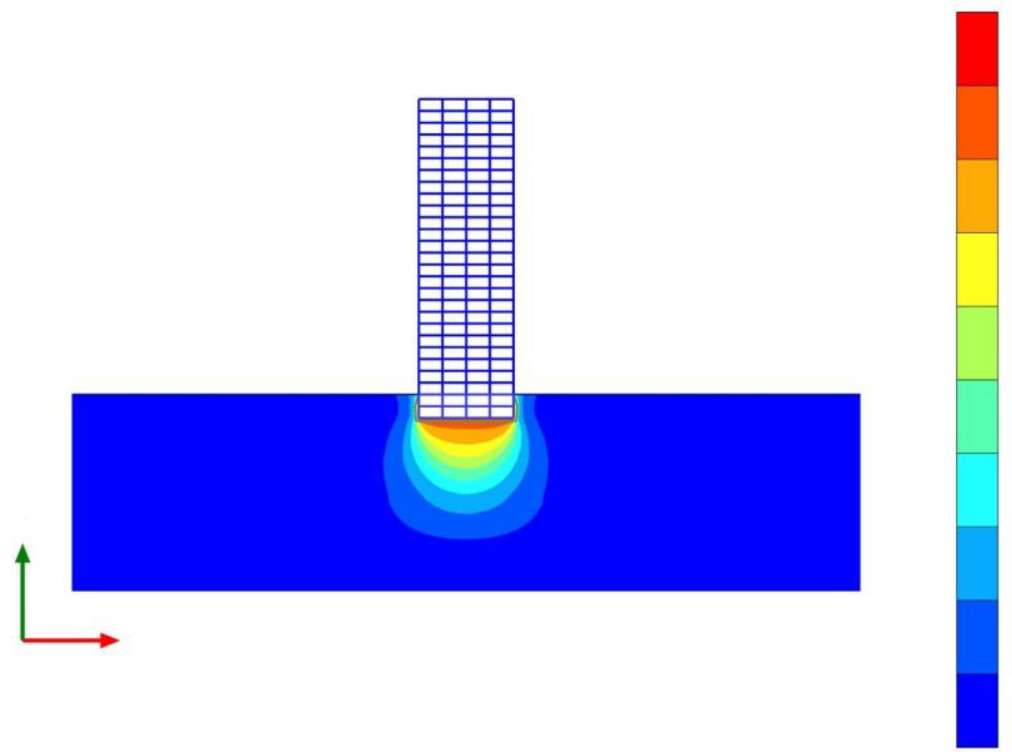

Fig. 2. Isolines of total displacements at the end of the construction phase of construction (dead load). The solution with SP PLAXIS 2D 2016.
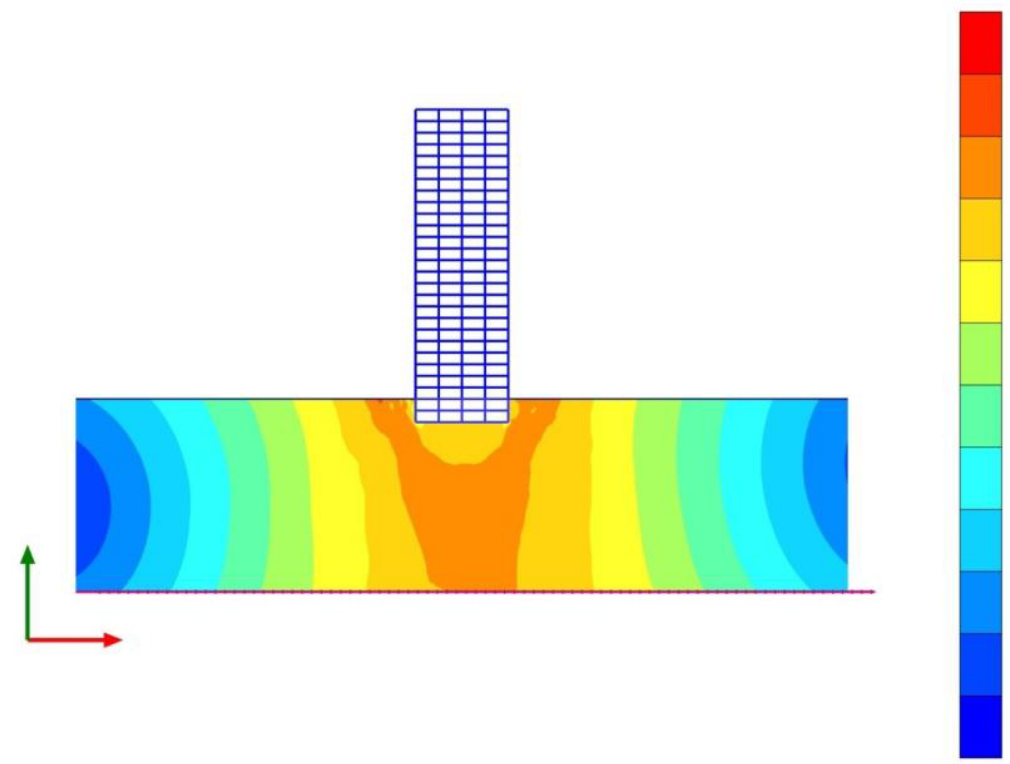

Fig. 3. Isolines of total residual displacements at the stage of completion of the seismic action (dynamic load). The solution with SP PLAXIS 2D 2016. 


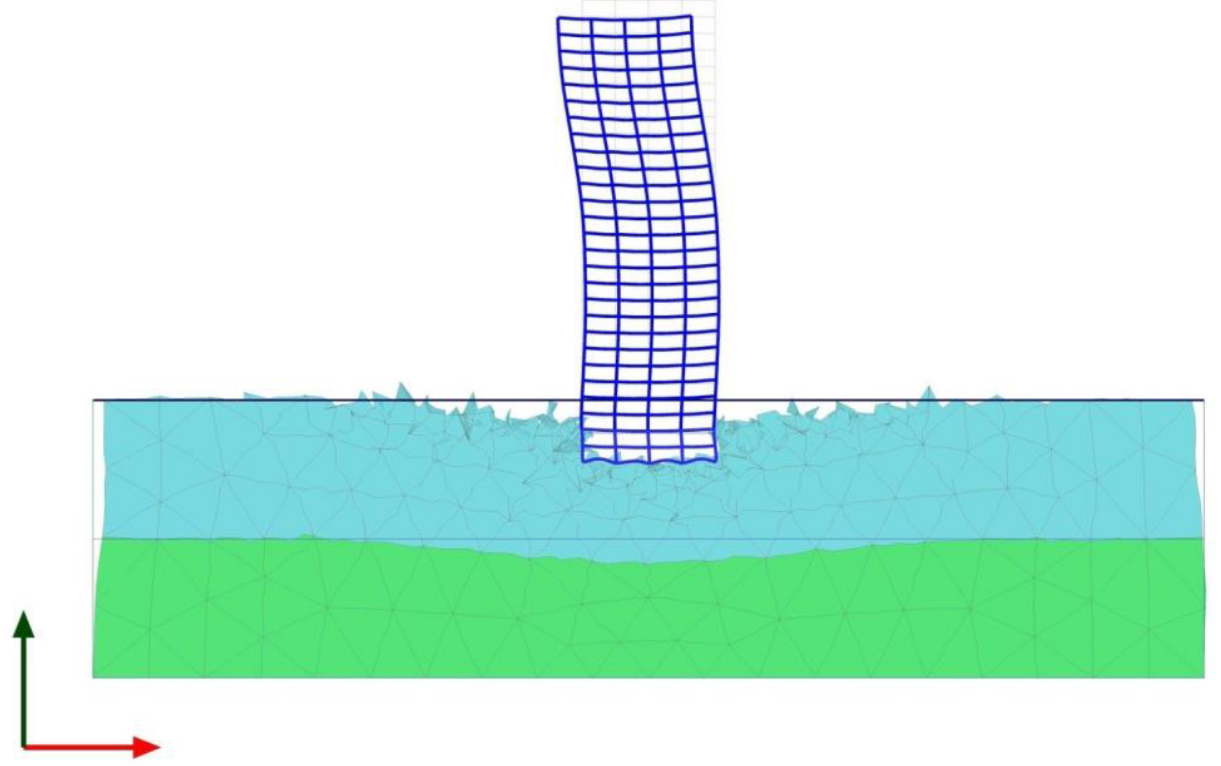

Fig. 4. The deformed grid of finite elements after the stage of the seismic action. The solution with SP PLAXIS 2D 2016.

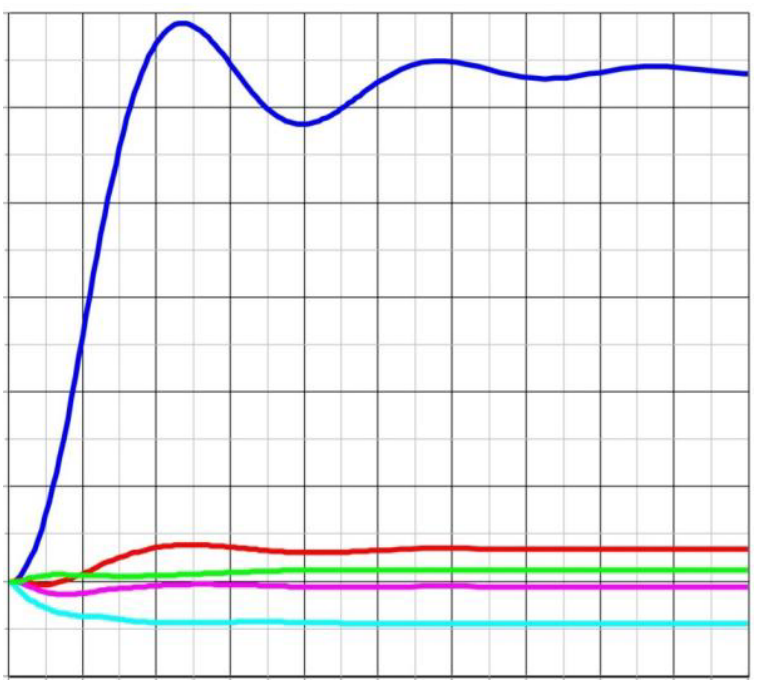

Fig. 5. Graphs of horizontal displacements dependence on duration of the seismic action. The values are given for different points located at different distances from the soil surface: Point $\mathrm{A}$ is at a distance of $+75 \mathrm{~m}$, Point $\mathrm{B}$ is at a distance of $0 \mathrm{~m}$ (on the ground-floor floor level), Point $\mathrm{C}$ is at 6 meters below the surface (base plate), Point $\mathrm{D}$ is $25 \mathrm{~m}$ below the surface, Point $\mathrm{E}$ is 50 meters below the surface. 


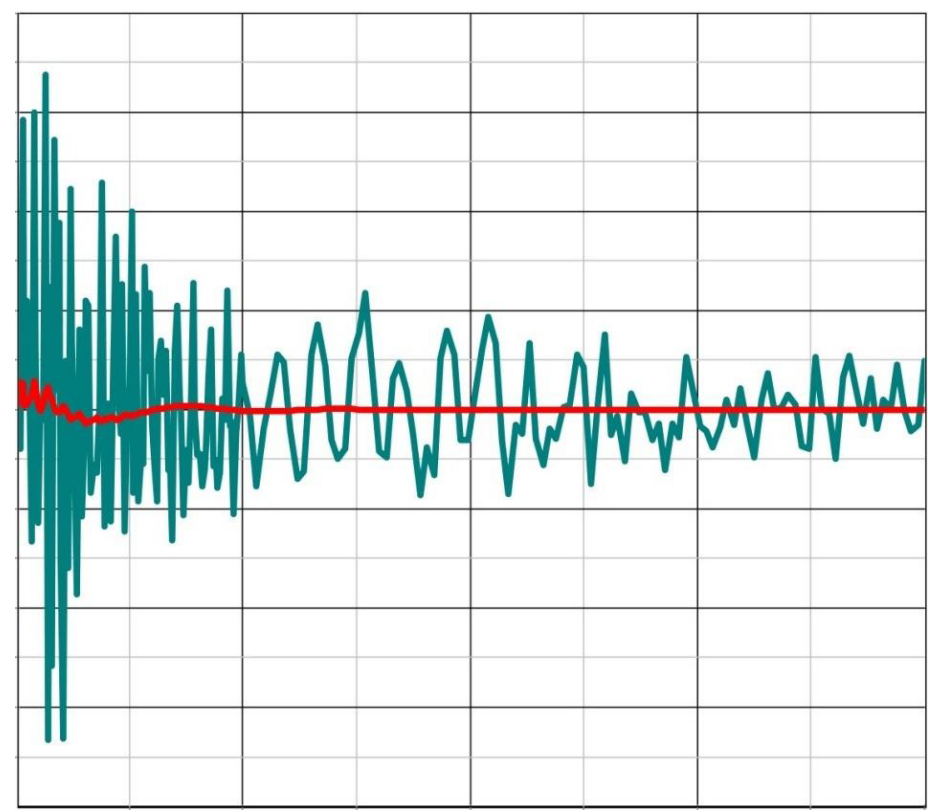

Fig. 6. Graphs of horizontal displacements dependence on duration of the seismic action. Red line marks acceleration at the top of the building $(75 \mathrm{~m})$, dark green line - at the level of $25 \mathrm{~m}$ below ground surface $(-25 \mathrm{~m})$.
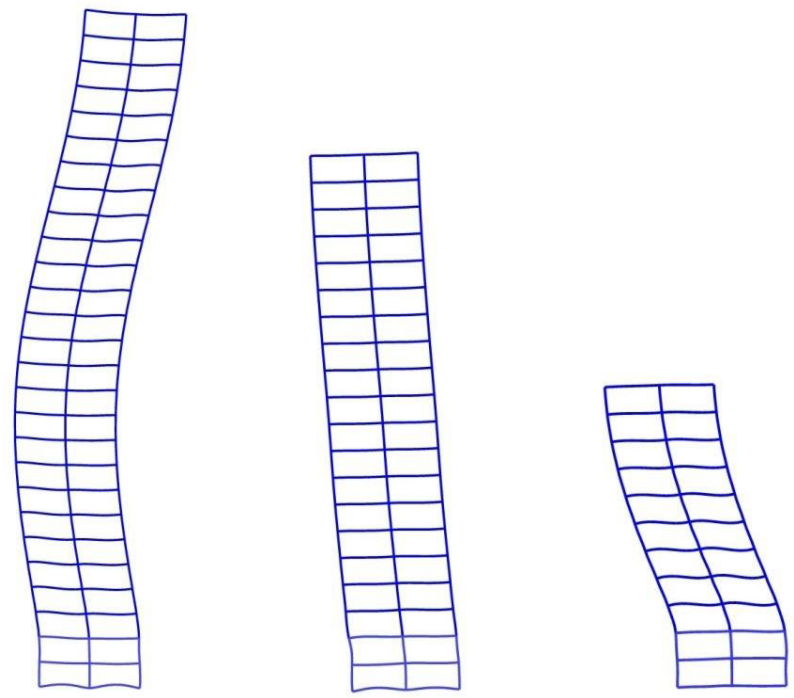

Fig. 7. Waveforms of superstructure parts at different heights. a) height of $75 \mathrm{~m}$; b) height of $54 \mathrm{~m}$; c) height of $27 \mathrm{~m}$.

\section{Conclusion}

1. The objective of collaboration of the system "foundation - structure" under seismic impacts is solved by taking into account the modeling of bearing structures of aboveground and underground parts of the structure, that has a significant impact on distribution and magnitude of the residual displacement of soil, in contrast to the method of constructions modeling as a solid array with reduced stiffness. 
2. In the Stress-Strain State of inhomogeneous soil foundation interacting with the structure under seismic impacts, is significantly affected by registration of stiffness of the structure itself, as well as of upper and lower layers of the base and their ratio (in the case of a two-layer base, considered in this paper) $[8,9,10]$.

3. Modeling of soil base under seismic action is performed by using the elastic-plastic hardening soil model for small deformations (hardening soil model with small-strain stiffness (HSSMALL), while taking into account soil stiffness at small deformations and its nonlinear dependence of the strain amplitude.

4. SSS calculations completed for double-layer base interacting with buildings of different heights and widths have shown that registration of elastic-plastic properties of soil under static and seismic effects leads to additional residual stresses and displacements [11].

5. Number of floors affects the waveform of above-ground parts of the building. With the growth of the construction height, the seismic load effect on the stress-strain state of the base soil increases. There are additional residual stresses and strains in the contact zone "foundation soil - foundation" which lead to additional residual stress and displacement, as well as to the formation of local zones of limit equilibrium.

\section{Acknowledgements}

This work was financially supported by the Ministry of Russian Education (state task \#2014/14)

\section{References}

1. H.T. Chan, Thesis on scientific degree competition of the candidate of technical sciences, 174 (2006)

2. K. Ishihara, NGO Georeconstruction-Fundamentproject, 384 (2006)

3. P.L. Ivanov, Gosenergoizdat, 259 (1962)

4. T. Iwasaki, K. Tokida, F. Tatsuoka, S. Watanabe, S. Yasuda, H. Sato, Proc. 3rd Int. Conf. On Microzonation. Seattle 3, 1319-1330 (1982)

5. M.N. Jaro, Thesis on scientific degree competition of the candidate of technical sciences 173 (2013)

6. I.T. Mirsayapov, I.V. Koroleva, G.Z. Zaripov, Soil Mechanics and Foundation Engineering in Geotechnical Engineering 1, 31-37 (2015)

7. H.B. Seed, I.M. Idriss, Journal of Soil Mechanics and Foundation Engeneering 97, 1249-1273 (1971)

8. H.B. Seed, Journal of Soil Mechanics and Foundation Engeneering 105, 201-255 (1996)

9. L.R. Stavnitser, Building schools Association, 448 (2010)

10. A.Z Ter-Martirosyan, A.Yy. Mirniy, E.S. Sobolev, Geotechnics 1, 66-72 (2016)

11. E.A. Voznesensky, V.V. Funikova, E.S. Kushnareva, V.G. Kovalenko, Exploration and conservation of mineral resources 12, 61-65 (2005) 